\title{
CME: Diabetes (136254): self-assessment questionnaire
}

\author{
Author: Edited by Tahseen A Chowdhury
}

\section{DOI: $10.7861 /$ clinmed.SAQ.21.4}

\section{SAQs and answers are ONLINE for RCP fellows} and collegiate members

\section{Format}

Candidates are asked to choose the best answer from the five possible answers. This best of five format is used in many medical examinations; however, the questions are not intended to be representative of those used in the MRCP(UK) Part 1 or Part 2 Written Examinations.

\section{The answering process}

1 Go to https://cme.rcplondon.ac.uk

2 Log on using your usual RCP username and password

3 Select the relevant CME question paper

4 Answer all 10 questions by selecting the best answer from the options provided

5 Once you have answered all the questions, click on Submit

\section{Registering your external CPD credits}

Carrying out this activity allows you to claim two external CPD credits. These will be automatically transferred to your CPD diary, where you can review the activity and claim your points.

1. A 21-year-old woman was admitted acutely with diabetic ketoacidosis as a first presentation of type 1 diabetes (T1D). She was stabilised with intravenous fluids and insulin, and was eating and drinking well. Plans were made to convert her to subcutaneous insulin. Her intravenous insulin requirements were a total of 36 units in the previous 24 hours.

\section{Which of the following is the most appropriate insulin regimen to commence?}

(a) Basal insulin, 36 units at night.

(b) Biphasic 30/70 (eg NovoMix 30) insulin, 18 units twice daily (bd).

(c) Biphasic 30/70 (eg NovoMix 30) insulin, 24 units in the morning and 12 units in the evening.

(d) Rapid acting insulin, 10 units with meals; and basal insulin, 6 units at night.

(e) Rapid acting insulin, 6 units with meals; and basal insulin, 18 units at night.

2. A 63-year-old woman with a 15-year history of type 2 diabetes (T2D) was admitted with a diabetic foot infection and treated with antibiotics. Her medication included metformin $1,000 \mathrm{mg}$ bd, gliclazide $160 \mathrm{mg}$ bd, and sitagliptin $100 \mathrm{mg}$ once daily. Glucose tests in hospital showed the following:

\begin{tabular}{lllll}
\hline & Morning & Pre-lunch & $\begin{array}{l}\text { Pre-evening } \\
\text { meal }\end{array}$ & Pre-bed \\
$\begin{array}{l}\text { Day } 1 \text { glucose, } \\
\text { mmol/L }\end{array}$ & 13.9 & 10.9 & 11.8 & 14.2 \\
$\begin{array}{l}\text { Day } 2 \text { glucose, } \\
\text { mmol/L }\end{array}$ & 12.3 & 11.7 & 12.6 & 15.2 \\
\hline
\end{tabular}

Which of the following is the most appropriate next step in her management?

(a) Add basal insulin analogue (eg Lantus), 10 units at night.

(b) Add empagliflozin, $10 \mathrm{mg}$ once daily.

(c) Add NPH insulin (eg Insulatard), 10 units at night.

(d) Add rapid acting insulin, 6 units with meals; and basal insulin, 18 units at night.

(e) No change.

3. A 45-year-old man was admitted with a symptomatic claudication and was awaiting angiography. He was on twice daily biphasic 30/70 mixed insulin (NovoMix 30), 42 units in the morning and 38 units in the evening. Blood glucose profile is shown:

\section{Morning Pre-lunch Pre-evening Pre-bed meal}

$\begin{array}{lllll}\text { Day } 1 \text { glucose, } & 7.2 & 11.2 & 15.8 & 9.2\end{array}$

$\mathrm{mmol} / \mathrm{L}$

$\begin{array}{lllll}\text { Day } 2 \text { glucose, } & 7.9 & 11.7 & 14.6 & 9.4\end{array}$

$\mathrm{mmol} / \mathrm{L}$

\section{Which of the following is the most appropriate} adjustment in insulin dose?

(a) 38 units in the morning and 38 units in the evening.

(b) 42 units in the morning and 42 units in the evening.

(c) 44 units in the morning and 42 units in the evening.

(d) 46 units in the morning and 38 units in the evening.

(e) No change in dose.

4. A 57-year-old man with a history of T2D underwent a deceased donor renal transplant, 5 years previously. His medication included tacrolimus $3 \mathrm{mg}$ bd, mycophenolate mofetil $500 \mathrm{mg}$ bd, prednisolone $5 \mathrm{mg}$ and metformin $500 \mathrm{mg}$ bd. His creatinine was $170 \mu \mathrm{mol} / \mathrm{L}$ (estimated glomerular filtration rate (eGFR) $33 \mathrm{~mL} / \mathrm{min} / 1.73 \mathrm{~m}^{2}$ ) and glycated haemoglobin $\left(\mathrm{HbA}_{1 \mathrm{c}}\right) 93 \mathrm{mmol} / \mathrm{mol}(10.7 \%)$. His body mass index (BMI) was $40 \mathrm{~kg} / \mathrm{m}^{2}$.

\section{Which of the following is the most appropriate next step in} his management?

(a) Add dapagliflozin, $5 \mathrm{mg}$ once daily.

(b) Add dulaglutide, $0.75 \mathrm{mg}$ once weekly.

(c) Add gliclazide, $80 \mathrm{mg}$ twice daily.

(d) Add rapid-acting (eg NovoRapid) insulin with breakfast.

(e) Increase metformin to $1,000 \mathrm{mg}$ bd. 
5. A 67-year-old woman with 20-year history of T2D, hypertension and ischaemic heart disease was seen in clinic. Her medication included ramipril $10 \mathrm{mg}$, bisoprolol $7.5 \mathrm{mg}$, aspirin $75 \mathrm{mg}$, simvastatin $40 \mathrm{mg}$, metformin $1,000 \mathrm{mg}$ bd and gliclazide $80 \mathrm{mg}$ bd. Her creatinine was $120 \mu \mathrm{mol} / \mathrm{L}\left(\mathrm{eGFR} 53 \mathrm{~mL} / \mathrm{min} / 1.73 \mathrm{~m}^{2}\right.$ ) and $\mathrm{HbA}_{1 \mathrm{c}}$ $69 \mathrm{mmol} / \mathrm{mol}$ (8.6\%). Her BMI was $24 \mathrm{~kg} / \mathrm{m}^{2}$. Blood pressure was $126 / 72 \mathrm{mmHg}$.

\section{Which of the following is the most appropriate next step in} her management?
(a) Add canagliflozin, $100 \mathrm{mg}$.
(b) Add insulin glargine (Lantus), 10 units at night.
(c) Add sitagliptin $100 \mathrm{mg}$.
(d) Increase gliclazide to $160 \mathrm{mg}$ bd
(e) No change.

6. A 43-year-old woman was recently diagnosed with T2D $\left(\mathrm{HbA}_{1 \mathrm{c}}\right.$ of $\left.54 \mathrm{mmol} / \mathrm{mol}\right)$. She was obese, with a BMI of $38 \mathrm{~kg} / \mathrm{m}^{2}$. She was very motivated and had read that she could 'reverse' her diabetes and wanted to know more.

\section{Which of the following options has the strongest evidence} for diabetes remission?

(a) Glucagon-like peptide-1 (GLP-1) agonist.

(b) Hypnotherapy.

(c) Orlistat therapy.

(d) Structured exercise programme.

(e) Total diet replacement (TDR) and bariatric surgery.

7. A 55-year-old man has been diagnosed with T2D for 7 years. Most recent $\mathrm{HbA}_{1 \mathrm{c}}$ was $68 \mathrm{mmol} / \mathrm{mol}$ and he was currently prescribed metformin, $1 \mathrm{~g}$ twice daily and gliclazide, $160 \mathrm{mg}$ twice daily. He was obese with a BMI of $38 \mathrm{~kg} / \mathrm{m}^{2}$ and reported struggling to lose weight over many years.

\section{Alongside lifestyle and dietary interventions, what medication adjustment would you suggest?}

(a) Decrease gliclazide to $40 \mathrm{mg}$, twice daily.

(b) No changes, he is on optimum diabetes management.

(c) Start DPP-4-inhibitor

(d) Start GLP-1 agonist.

(e) Start insulin.

8. A 25-year-old woman with T1D was admitted to hospital with an acute exacerbation of asthma. On routine checking, her capillary blood glucose (CBG) level was $18 \mathrm{mmol} / \mathrm{L}$. She has previously attended structured education, is confident with DAFNE principles and usually has very good glycaemic control. She usually took Lantus, 14 units in the evening, and NovoRapid (dose dependant on carbohydrate portion), with meals. She managed to eat her lunch shortly before presenting to the emergency department.
What is the most appropriate next step in her diabetes management?

(a) Check her capillary blood ketones.

(b) Start a variable rate insulin infusion (VRII) and continue her Lantus.

(c) Start intravenous fluids.

(d) This woman is competent at self-managing her diabetes, allow her to calculate and administer a correction dose to bring her blood glucose back to target range.

(e) Using the formula: 1 unit of NovoRapid to lower CBGs by $3 \mathrm{mmol} / \mathrm{L}$, prescribe 3 units of NovoRapid to bring her blood glucose back to target range.

9. A 45-year-old White lady was diagnosed with diabetes by her general practitioner (GP) 3 months ago. She has a history of rheumatoid arthritis and had not been taking any steroids including steroid injections. She was lean with a BMI of $20 \mathrm{~kg} / \mathrm{m}^{2}$. Her $\mathrm{HbA}_{1 \mathrm{c}}$ was $61 \mathrm{mmol} /$ $\mathrm{mol}$ ( $<42 \mathrm{mmol} / \mathrm{L}$ ) on diagnosis and she was started on metformin and gliclazide by her GP which improved her $\mathrm{HbA}_{1 \mathrm{c}}$ to $54 \mathrm{mmol} / \mathrm{mol}$. Her C-peptide was $700 \mathrm{pmol} / \mathrm{L}$ (370-1,470 pmol/L) with paired glucose of $10 \mathrm{mmol} / \mathrm{L}$ and she had strongly positive GAD65 antibodies.

\section{What would be the next course of action?}

(a) Admit to hospital for monitoring.

(b) Continue current medications.

(c) Maturity onset diabetes of the young (MODY) genetic testing.

(d) Start insulin.

(e) Stop gliclazide.

10. A 25-year-old White lady had her CBG check during a health check-up at her workplace because she had a strong family history of diabetes. She was told to visit her GP to have further tests. At her GP, her non-fasting CBG was $9.2 \mathrm{mmol} / \mathrm{L}$ and her urinary ketones were negative. Further tests showed $\mathrm{HbA}_{1 \mathrm{c}} 52 \mathrm{mmol} / \mathrm{L}$ ( $<42 \mathrm{mmol} / \mathrm{L}$ ), negative autoantibodies and C-peptide $1,100 \mathrm{pmol} / \mathrm{L}$ (370-1,470 pmol/L). She had a BMI of $20 \mathrm{~kg} / \mathrm{m}^{2}$. On further questioning, her father had diabetes diagnosed at age 28 and is not on insulin. She has two brothers, one who also has diabetes.

\section{What is the likely diagnosis?}

(a) Ketosis-prone diabetes.

(b) Latent autoimmune diabetes in adults (LADA).

(c) MODY.

(d) T1D.

(e) T2D.

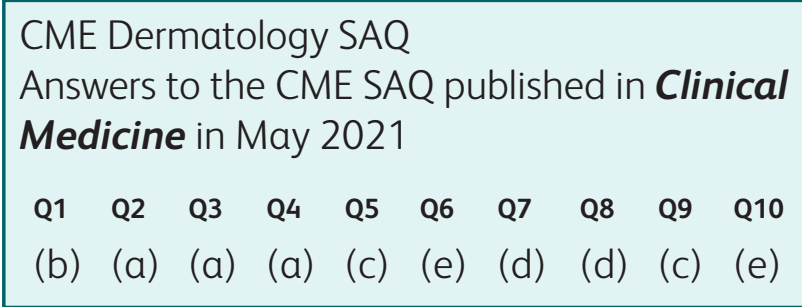

